\title{
The Combined Effects of Wood Vinegar and Perfluorooctanoic Acid on Enzymatic Activities, DNA Integrity and Gene Transcription in Dugesia Japonica
}

\section{Jianyong Zhang}

Shandong University of Technology - West Campus: Shandong University of Technology

Na Sun

Shandong University of Technology - West Campus: Shandong University of Technology Jingyi Sun

Shandong University of Technology - West Campus: Shandong University of Technology Bin Wang

Shandong University of Technology - West Campus: Shandong University of Technology Xiaoran Chen

Shandong University of Technology - West Campus: Shandong University of Technology

\section{Ziheng Lv}

Shandong University of Technology - West Campus: Shandong University of Technology Jing Liu

Shandong University of Technology - West Campus: Shandong University of Technology

\section{Bosheng Zhao}

Shandong University of Technology - West Campus: Shandong University of Technology

\section{Zuoqing Yuan ( $\nabla$ yuanzuoqing2008@126.com )}

Shandong University of Technology https://orcid.org/0000-0002-5371-0298

\section{Research Article}

Keywords: Dugesia japonica, Perfluorooctanoic acid, Wood vinegar, Enzyme activities, DNA damage, Gene expression

Posted Date: October 18th, 2021

DOl: https://doi.org/10.21203/rs.3.rs-906219/v1

License: (9) (1) This work is licensed under a Creative Commons Attribution 4.0 International License. Read Full License 


\section{Abstract}

Perfluorooctanoic acid (PFOA) has been identified widely in aquatic environments, while there are few reports detailing the environmental risk of wood vinegar (WV) on freshwater ecosystems. We used freshwater planarians, Dugesia japonica, to evaluate the combined effects of PFOA and WV by examining the adverse influence of enzymatic activities, DNA damage and gene transcription on planarians. Compared with control and PFOA groups, the malonaldehyde content was lower in planarians treated with WV. In addition, WV enhanced the activities of antioxidant enzymes and mitochondrial enzymes, relieving the toxicity effects of PFOA. We also studied the genotoxicity of PFOA and WV on planarians using the comet assay. WV decreased the proportion of DNA in the tail and the olive tail moment. Furthermore, expression of $g p x, g s t$ and gr genes in planarians was significantly altered following exposure to both PFOA and WV, compared with individual exposure. Our results suggest that WV could alleviate the adverse effects of PFOA on the aquatic environment, but ecological risk assessments and toxicological safety evaluations of WV are necessary.

\section{Introduction}

Wood vinegar (WV), also called pyroligneous acid, is a byproduct of wood carbonization during slow pyrolysis. It is a reddish-brown aqueous liquid rich in oxygenated compounds (Mathew and Zakaria, 2015). Although WV is recognized as safe, the environmental and biological risks of WV need to be further evaluated because of its complex composition (Zulkarami et al. 2011). WV has a variety of biological activities, such as antioxidant, antibacterial, antifungal and termiticidal (Petchpoung et al., 2020; Yang et al., 2016; Oramahi and Yoshimura, 2013; Akakabe et al., 2006), and is also thought to regulate gene expression (Huo, et al., 2016), promote plant growth (Polthanee et al., 2015) and improve animal health (Yan et al., 2012). Biochar blended with WV can be used as a soil amendment to reduce the potential environmental risks of herbicides to aquatic environments (Zhang et al., 2020; Hagner et al., 2013). WV enters soil and water environments through production activities or emissions. Previous studies have focused on the biological activities of WV. However, there are no reports focusing on the potential environmental and ecological risks to freshwater organisms and ecosystems. Perfluorooctanoic acid (PFOA) has been discovered in organisms and the environment, particularly as an environmental pollutant in aquatic environments (Lindstrom et al., 2011; Hu et al., 2016), resulting in a variety of toxicological effects (Li et al., 2017). PFOA causes acute toxic effects (Yuan et al., 2015), oxidative stress (Feng et al., 2017), cell apoptosis (Liu et al., 2007), mitochondrial dysfunction (Yuan et al., 2016) and decreased enzymatic activities (Yuan et al., 2014). Therefore, evaluation of the combined effects of WV and PFOA on aquatic organisms is important.

Dugesia japonica is an ideal model organism for risk assessment and toxicological research in freshwater ecosystems (Ireland et al., 2020). Planaria showed a series of sensitive and reliable responses to environmental pollutants and environmental pressure (Yuan et al., 2017). The research also shows that the behavior and regeneration of planarians have changed in the face of environmental pollutants (Yuan et al., 2015). Thus, through employment of planarians, we can better understand the antioxidative effects, 
environmental risks and combined influence of WV and PFOA on freshwater organisms. In a previous study, we analyzed the chemical composition, antioxidant capacities and free radical scavenging capacities of WV (Wang et al., 2020). In the current study, we investigated the effects of exposure to WV and PFOA individually or together on (1) malonaldehyde (MDA) content, catalase (CAT) and superoxide dismutase (SOD) activities; (2) glutathione S-transferase (GST), glutathione peroxidase (GPx) and glutathione reductase (GR) activities; (3) cytochrome oxidase (COX), succinate dehydrogenase (SDH) and monoamine oxidase (MAO) activities; (4) DNA damage; and (5) transcription of glutathione-S-transferase $(g s t)$, glutathione peroxidase $(g p x)$ and glutathione reductase $(g r)$ genes. We used these biomarkers to provide a preliminary assessment of the ecotoxicological risks of WV and deepen our understanding of the impact of WV on the aquatic environment.

\section{Methods}

\section{Materials and Animal handling}

The D. japonica was collected as described previously (Yuan et al., 2016). PFOA was purchased from Sigma-Aldrich Chemical Co. (St. Louis, MO, USA) and dissolved in autoclaved distilled water containing $0.005 \%(\mathrm{v} / \mathrm{v}$ ) dimethyl sulfoxide (DMSO) to the desired concentrations. WV was prepared from blended wood and refined for the following experiments.

Intact planarians were soaked in autoclaved tap water supplemented with 0 or $15 \mathrm{mg} / \mathrm{L}$ PFOA, $1 \mathrm{mg} / \mathrm{L}$ WV, $15 \mathrm{mg} / \mathrm{L}$ PFOA $+1 \mathrm{mg} / \mathrm{L} \mathrm{WV}$ or $15 \mathrm{mg} / \mathrm{L} P F O A+0.83 \mathrm{mg} / \mathrm{L} \mathrm{WV}$, respectively. Each treatment contained 90 planarians and was repeated three times. The solutions of all treatment groups were changed every $12 \mathrm{~h}$. Planarians were collected from all treatment groups and examined according to the methods below on days $1,3,7$ and 10 .

\section{MDA levels and antioxidant enzyme activities}

MDA levels and enzyme activities in tissue homogenate supernatants were measured using assay kits according to manufacturer's instructions (Beyotime, Shanghai, China). Activities of CAT and SOD were measured using the method of Yuan et al. (2014). The Bradford method with bovine serum albumin as a standard was used to measure protein contents in tissue homogenate.

\section{Mitochondrial enzyme activities}

Mitochondria of all treatment groups were isolated using a Mitochondria Isolation Kit (Beyotime, Shanghai, China). Activities of SDH, COX and MAO were determined using the method of Yuan et al. (2016). Protein contents were determined using the Bradford method.

\section{Comet assay}

Planarians were shredded and rinsed three times in a $1.5 \mathrm{~mL}$ microcentrifuge tube containing phosphatebuffered saline (PBS) buffer. Tissues were digested for $10 \mathrm{~min}$ at $20^{\circ} \mathrm{C}$ using trypsin solution $(1 \mathrm{~mL}, 1 \%$, $\mathrm{v} / \mathrm{v})$. The supernatant was discarded, and cells were resuspended in $1 \mathrm{~mL}$ PBS buffer after low 
temperature centrifugation for $5 \mathrm{~min}$ at $2,000 \mathrm{~g}$. The cell suspension was filtered using a cell sieve. Following centrifugation for $5 \mathrm{~min}$ at $2,000 \mathrm{~g}$ and $4^{\circ} \mathrm{C}$, cells were resuspended in $20 \mu \mathrm{L}$ PBS buffer. A mixture of $50 \mu \mathrm{L}$ low melting point agarose $(0.5 \%, \mathrm{w} / \mathrm{v})$ and $5 \mu \mathrm{L}$ trypsin-treated cell suspension were spread on slides (Trevigen, MD, USA) and allowed to solidify. These slides were immersed in cell lysing solution (10 mM Tris-HCl, 2.5 M EDTA, 1\% SDS, 1\% Triton X-100 and 10\% DMSO, pH 10) for 60 min at $4^{\circ} \mathrm{C}$. The slides were then rinsed three times using PBS buffer and immediately immersed in alkaline electrophoresis buffer ( $1 \mathrm{mM}$ EDTA, $300 \mathrm{mM} \mathrm{NaOH}, \mathrm{pH} 13)$ to unwind DNA for $0.5 \mathrm{~h}$ at $4^{\circ} \mathrm{C}$. Slides were subjected to electrophoresis for $20 \mathrm{~min}$ at $30 \mathrm{~V}$ and then placed in cold neutralization buffer $(0.4 \mathrm{M}$ Tris$\mathrm{HCl}, \mathrm{pH}$ 7.5) for $10 \mathrm{~min}$. The slides were then stained with $1 \mathrm{mg} / \mathrm{mL}$ DAPI for $40 \mathrm{~min}$ and washed twice for 5 min each time at $4^{\circ} \mathrm{C}$. Subsequently, the slides were examined using a fluorescence microscope (Olympus DP80, Tokyo, Japan). A total of 150 cells were analyzed for each treatment using the comet assay software project (CASP, version 1.2.3b1, San Francisco, CA, USA). The concentration of DNA in the tail and the olive tail moment related to DNA damage were determined.

\section{Quantitative reverse-transcription PCR (qRT-PCR)}

Total RNA was extracted using Trizol reagent (Thermo Scientific, Waltham, MA, USA), and cDNA was synthesized using ReverTra Ace qPCR RT Master Mix (Toyobo, Osaka, Japan). qRT-PCR was carried out on an LightCycler 480 II real-time PCR system (Roche, Basel, Switzerland) using a SYBR real-time PCR mixture (BioTeke, Beijing, China). Primer sequences of genes to be tested and the internal reference gene ( $\beta$-actin) for qRT-PCR are listed in Table 1. Relative expression levels were calculated from three replicates of each sample for all treatment groups.

Table 1

Genes and primers used in SYBR quantitative RT-PCR analysis.

\begin{tabular}{|lll|}
\hline Genes & Forward primers $\left(\mathbf{5}^{\prime} \mathbf{3}^{\prime} \mathbf{)}\right.$ & Reverse primers $\left(\mathbf{5}^{\prime} \mathbf{3}^{\prime} \mathbf{)}\right.$ \\
\hline$g p x$ & AAGCAAGAGCCACAAAC & GGATATTCGGATTGGTC \\
\hline$g s t$ & CATTGGCTTATGGGTGAA & CTTCGCAATAGGCTCCA \\
\hline$g r$ & GCCTGAAGAAGATGCTA & ACAATCATTATCGCCTC \\
\hline Dj $\beta$-actin & ACACCGTACCAATCTATG & GTGAAACTGTAACCTCG \\
\hline
\end{tabular}

\section{Statistical analysis}

Statistical comparisons were made by one-way analysis of variance (ANOVA) using the Statistical Package for the Social Sciences for Windows (SPSS, version 16.0; Chicago, IL, USA), and P< 0.05 was considered to be significant. Data were recorded as mean and standard deviation (SD).

\section{Results}

\section{MDA levels and antioxidant enzyme activities}


MDA levels in after exposure to PFOA or WV are shown in Fig. 1. Compared with the control, MDA levels were significantly higher in the PFOA treatment group $(P<0.05)$. At first, MDA levels of the WV group were only slightly lower than those in the control, but they were significantly lower from days 7 to $10(P<0.01)$. Moreover, co-application of PFOA and WV significantly decreased MDA levels compared with the control after day $7(P<0.01)$. MDA levels in the WV group were significantly lower than those in the PFOA group across the whole experimental period. From day 7, MDA levels were significantly lower in the two coapplication groups than in the PFOA group. These results showed that WV can alleviate increased MDA contents caused by PFOA.

Changes in activities of five antioxidant-related enzymes after planarians were exposed to PFOA or WV are shown in Fig. 2 and Fig. 3. SOD activities were higher on day 3 and then inhibited at later timepoints $(P<0.05)$ in the PFOA group compared with the control (Fig. 2a). Significant increases in SOD activity were observed in the WV treatment group compared with the control group on day $10(P<0.01)$. However, SOD activity was significantly higher than that of the control on day $7(P<0.05)$ and day $10(P<0.01)$ in the two co-application groups. WV induced higher SOD activity than PFOA from day $7(P<0.01)$. Interestingly, SOD activities in the co-application groups were significantly lower than that in the PFOA group on day $3(P<0.05)$, but were significantly higher during the second half of the experiment $(P<$ 0.01). CAT activities were inhibited in the PFOA group (Fig. 2b) and not significantly higher in the WV group before day 10 , compared with the control $(P<0.05)$. CAT activity in the $1 \mathrm{mg} / \mathrm{L} \mathrm{WV}$ co-application group was higher than that in the control on day $1(P<0.05)$. CAT activity in the WV group was higher on days 1 and $10(P<0.01)$ compared with that in the PFOA group. Moreover, significantly higher CAT activities compared with those in the PFOA group were observed in the $1 \mathrm{mg} / \mathrm{L} \mathrm{WV}$ co-application group on days 1 and $10(P<0.01)$, and in the other WV co-application group on day $1(P<0.05)$ and day $10(P<$ 0.01). These results were consistent with the results of MDA content.

In comparison with the control, GPx activity showed a trend of inhibition and then increase with prolonged exposure to PFOA (Fig. 3a). However, WV significantly increased GPx activities compared with the control from day 1 to day $10(P<0.01)$. Co-application of WV and PFOA also induced significantly higher GPx enzyme activity $(P<0.01)$ on day 10 . GPx activities were significantly higher under WV treatment $(P<0.05)$ than under PFOA treatment. In the two co-application groups, GPx activities were significantly higher on days 3 and 10 than those in the PFOA group $(P<0.01)$. Overall, GPx activities were significantly higher than those of the control in all groups involving WV application.

As shown in Fig. 3b, GST activities showed a trend of activation in all groups with treatment time. PFOA treatment resulted in significantly higher GST activities on day $3(P<0.05)$ and day $10(P<0.01)$ compared with the control. Meanwhile, WV application alone or in combination with PFOA caused significant activation of enzyme activity compared with the control on day $7(P<0.05)$ and day $10(P<$ 0.01). There were no significant differences in GST activity between WV and PFOA treatments. However, 1 $\mathrm{mg} / \mathrm{L}$ WV co-application treatment produced lower GST activities than that in the PFOA group on day 3 $(P<0.05)$ and day $10(P<0.05)$, with similar results observed in the $0.83 \mathrm{mg} / \mathrm{L} \mathrm{WV}$ co-application group on day $3(P<0.05)$ and day $10(P<0.01)$. 
Changes in GR activity are presented in Fig. 3c. GR activities were inhibited on day 1 and then activated on day $7(P<0.05)$ in the PFOA group compared with the control. However, WV alone significantly increased GR activities compared with the control from day 3. Co-application of $1 \mathrm{mg} / \mathrm{L} \mathrm{WV}$ and PFOA resulted in higher GR activities than those in the control. GR activities in the $0.83 \mathrm{mg} / \mathrm{L} W V$ co-application group were significantly higher on day $1(P<0.01)$ and day $7(P<0.01)$ than those in the control. In comparison with the PFOA group, GR activities were significantly higher in the WV group and the WV coapplication group within 10 days of treatment. Meanwhile, co-application treatment with $0.83 \mathrm{mg} / \mathrm{L} \mathrm{WV}$ resulted in higher GR activities on day $1(P<0.01)$ and day $7(P<0.05)$ compared with the PFOA group. These results show that WV attenuated the effects of PFOA owing to the antioxidant capacity of WV.

\section{COX, MAO and SDH activities}

COX, MAO and SDH activities after planarians were exposed to PFOA or WV are shown in Fig. 4. Before day 7, COX activities after exposure to PFOA were significantly lower than those in the control $(P<0.05$; Fig. 4a). WV treatment induced higher COX activities on day $1(P<0.01)$ and day $7(P<0.01)$. Coapplication of $1 \mathrm{mg} / \mathrm{L} \mathrm{WV}$ and PFOA resulted in significantly lower COX activity on day 3 and then higher activity after day $7(P<0.01)$, compared with the control. In the $0.83 \mathrm{mg} / \mathrm{L} \mathrm{WV} \mathrm{co-application} \mathrm{group,} \mathrm{COX}$ activities also were significantly lower than those in the control until day $3(P<0.01)$ and were then higher after day $7(P<0.05)$. In comparison with the PFOA group, WV caused significantly higher COX activities $(P<0.01)$. Co-application of $1 \mathrm{mg} / \mathrm{L} W V$ with PFOA resulted in a general increase in COX activity, but inhibition of activity on day $3(P<0.01)$. Co-application of $0.83 \mathrm{mg} / \mathrm{L} \mathrm{WV}$ with PFOA resulted in lower COX activity than that observed in the PFOA group on day 3 but higher activity on day $10(P<0.01)$.

MAO activity was activated by PFOA before day 7 and then inhibited by PFOA on day $10(P<0.05)$, compared with the control (Fig. 4b). WV significantly enhanced MAO activities compared with the control on day $10(P<0.05)$. MAO activities showed no significant difference from those of the control in coapplication groups. In comparison with the PFOA group, MAO activity in the WV group was significantly inhibited on day 3 and then enhanced on day $10(P<0.01)$. In the two WV co-application groups, MAO activities were lower than those in the PFAO group on day $1(P<0.05)$ and then higher on day $10(P<$ 0.05).

PFAO significantly inhibited SDH activities compared with those of the control (Fig. 4c). SDH activity was significantly higher on day 10 in the WV group compared with the control $(P<0.05)$. Significant inhibition on days $1(P<0.05)$ and $3(P<0.01)$ and then an increase in SDH activity compared with the control on day 10 was detected in the two co-application groups. WV significantly increased SDH activity compared with that in the PFOA group on days $3(P<0.01)$ and $10(P<0.05)$. In the two co-application groups, SDH activities were significantly higher than those in the PFOA group from day 3 .

\section{DNA damage}

DNA damage measurements after planarians were exposed to PFOA or WV are presented in Fig. 5. The percentage of DNA in the tail was higher on days 3 and $7(P<0.01)$ in the PFOA group compared with the control (Fig. 5a). WV caused a significant increase in DNA in the tail at first, which then decreased. Co- 
application of PFOA and WV only resulted in more DNA in the tail compared with the control on day 3. Compared with the PFOA group, we observed significantly less DNA in the tail on days 3 and 7 in the WV group and the two co-application groups $(P<0.01)$. Olive tail moment was consistent with DNA in the tail (Fig. 5b). These two DNA damage parameters indicated that a low concentration of WV can alleviate DNA damage caused by PFOA.

\section{Gene expression}

We analyzed expression profiles of three genes related to glutathione metabolism ( $g p x, g s t$ and $g r$ ) by qRT-PCR (Fig. 6). Treatment with PFOA resulted in a significant decrease in gpx expression compared with the control before day $10(P<0.01)$ and on day $10(P<0.05)$ (Fig. 6a). WV decreased gpx expression, but this was not significant on day 10 . Co-application of $1 \mathrm{mg} / \mathrm{L}$ WV with PFOA decreased $g p x$ expression compared with the control before day $10(P<0.01)$ and then enhanced expression on day 10 . In the 0.83 $\mathrm{mg} / \mathrm{L}$ WV co-application group, gpx expression was lower than that in the control and only higher on day $3(P<0.05)$. Treatment with WV alone produced higher gpx expression than PFOA on days 1 and $3(P<$ 0.01). In co-application of PFOA with $1 \mathrm{mg} / \mathrm{L} \mathrm{WV}, g p x$ expression was significantly higher on day 3 ( $P<$ $0.05), 7(P<0.01)$ and $10(P<0.01)$ compared with that with PFOA alone. Co-application of $0.83 \mathrm{mg} / \mathrm{L}$ WV and PFOA first caused higher $(P<0.01)$ and then lower gpx expression compared with PFOA treatment alone.

gst gene expression was significantly down-regulated first $(P<0.01)$ and then up-regulated $(P<0.01)$ over time in all treatment groups (Fig. 6b). Meanwhile, compared with the PFOA group, gst expression was first lower in the WV group $(P<0.05)$ and then higher $(P<0.01)$. In the two WV co-application groups, $g s t$ expression was significantly higher than that int eh PFOA group from day 3 to day $10(P<0.05)$.

gr expression was lower in the PFOA group than in the control $(P<0.01)$, except on day 3 (Fig. 6c). Compared with the control, WV significantly reduced gr expression on days 1,7 and $10(P<0.01)$. However, co-application of PFOA and WV significantly up-regulated gr expression on days 3 and 7 ( $P<$ 0.01). Compared with the PFOA group, WV cause higher gr expression on days 1 and 10, but lower expression on days 3 and 7. In the two co-application groups, gr expression was higher than that in the PFOA group, except on the third day $(P<0.01)$. WV therefore alleviated the adverse effect on gene expression caused by PFOA to some extent.

\section{Discussion}

A variety of different organic products can be produced by pyrolysis reactions of biomass at high temperature (Mathew et al., 2015). Therefore, the composition of WV is complex. Many studies have indicated that WV is rich in phenolic compounds (Ma et al., 2011), which endows WV with antioxidant capacity (Yang et al., 2016) as well as scavenging radical capacity (Loo et al., 2007). Free radicals can destroy lipids, proteins and DNA through oxidative damage (Pietta, 2000). Therefore, there is a desire to discover natural compounds that can remove reactive oxygen species and have strong scavenging capacity. The scavenging effects of WV are in the order of superoxide anion radical > diphenyl bitter acyl 
radicals > hydroxyl radical (Wei et al., 2010). Our previous research showed that WV significantly decreases superoxide radical contents and the IC50 value was $18.306 \mathrm{mg} / \mathrm{mL}$ (Wang et al., 2020). WV is therefore more effective at scavenging $\mathrm{O}^{2-}$ radicals than $\mathrm{DPPH}$ or $\cdot \mathrm{OH}$ radicals.

These results indicate that WV could potentially be a natural antioxidant and relieve oxidative stress (Wei et al., 2010; Cai et al., 2012). However, there are no reports on the effect of WV on antioxidant enzyme activities in freshwater organisms. MDA and antioxidant enzymes activities indicate levels of oxidative stress and redox in organisms, and both are impacted by PFOA (Stahl et al., 2011; Yuan, et al., 2017). In this study, lipid peroxidation was alleviated by application or co-application of WV. SOD activities showed a significant change at the same time. $\mathrm{H}_{2} \mathrm{O}_{2}$ produced in the process of SOD catalysis can be removed by CAT (Xu et al., 2013). CAT activities decreased with PFOA exposure of 1 to 10 days. These results indicate that PFOA destroyed the antioxidant enzyme system. However, CAT activities were increased in WV and co-application groups, indicating that WV attenuated the inhibition of PFOA and activated enzyme activities.

GPx can increase the content of GSH, and then GSH can inhibit lipid peroxidation and reduce the content of MDA (Feng et al., 2015; Stockwell et al., 2017). However, the activity of GPx was inhibited by PFOA in our study, leading to an increase in MDA content. At the same time, WV activated enzyme activities and attenuated the inhibition of PFOA in WV co-application groups. GST is involved in detoxification in cells. In our study, GST activities were increased in all treatment groups with WV or PFOA. Changes in GST activities may be due to the toxicity of PFOA and complex chemical constituents of WV. Therefore, alteration of GST activities indicates that PFOA and WV affected oxidative stress-related processes in planarians. GR maintains the reduced status of glutathione (GSH) in cells. PFOA treatment resulted in oxidative stress and inhibited GR activities. WV, as a free radical scavenger, may have elevated levels of GSH and improved tolerance to PFOA by activating GR activities in WV co-application groups.

COX, MAO and SDH are localized to the mitochondrial membrane. PFOA induces dysregulation resulting in oxidative stress (Yuan et al., 2016). COX binds to the mitochondrial membrane and participates in electron transfer (Srinivasan and Avadhani, 2012). PFOA and WV increase the activities of COX. These changes in enzymatic activities may be due to mitochondrial dysfunction caused by PFOA (Huang et al., 2013). WV probably increased the activities of COX because it is rich in organic acids and participates in the pumping out of protons. MAO is a key enzyme in the outer mitochondrial membrane and plays a role in amine metabolism (Lisa et al., 2009). In this study, MAO activities were significantly activated at first and then inhibited by PFOA, implying that MAO activities increased due to PFOA stress and then decreased as a result of tolerance to PFOA. Because WV is an acid liquid, it can increase MAO enzyme activity. The activity of SDH is closely related to the function of mitochondria. In this study, increase in SDH activity indicated that mitochondrial function was increased under PFOA tress. By contrast, WV decreased SDH activity. This may have been due to antioxidant activities of WV. In general, the above experimental results show that WV functions in biochemical protection of planarians. 
We determined DNA damage using comet assays after exposure of planarians to PFOA or WV. PFOA exerts genotoxic effects on paramecium (Kawamoto et al., 2010), HepG2 cells (Wielsøe et al., 2015) and humans (Franken et al., 2017) through DNA oxidative damage caused by intracellular reactive oxygen species. WV reduced the olive tail moment and DNA in the tail (\%), thus alleviating DNA damage caused by PFOA. The alleviating effects of WV may be closely related to its free radical scavenging abilities. The mechanism of free radical scavenging abilities of WV in planarians remains to be further studied. We observed significant effects on gpx, gst and grgene expression by treatment with PFOA or WV. Changes in gpx expression were consistent with changes in enzyme activities. There was a trend of gene expression being down-regulated by PFOA treatment and then up-regulated. WV stabilized gpx expression to protect planarians against oxidative stress. gst mRNA expression was down-regulated and then upregulated following co-application of PFOA and WV. These results showed that gst is involved in alleviating stress caused by PFOA through detoxification. Our experimental data showed that GR activities and grexpression levels were inhibited under PFOA stress at the beginning of the experiment. Moreover, grgene expression was significantly increased in groups administered WV but maintained a similar trend to that in the control group. However, the regulation of gene expression needs further research due to the complex components of WV.

\section{Conclusion}

Oxidative stress biomarkers, including MDA content, antioxidative enzymatic activities, DNA oxidative damage and antioxidative gene expression, were examined in planarians after exposure to WV and/or PFOA. The antioxidant capacity of WV could reduce the adverse effects of PFOA by improving enzymatic activities, protecting DNA from damage and regulating gene expression. Therefore, WV could be used as a source of antioxidants, but ecological risk assessments and toxicological safety evaluations of WV are necessary. It is also necessary to investigate the effects of WV on other biomarkers of organism health in future studies.

\section{Declarations}

Ethics approval and consent to participate The experiment is in accordance with the care and animal wellbeing legislation of China. The research was authorized by the Animal ethics committee of Shandong University of Technology, Zibo, China. This paper has no investigation based on human parts.

\section{Consent for publication Not applicable}

Availability of data and materials The datasets used and/or analysed during the current study are available from the corresponding author on reasonable request.

Competing interests The authors declare that there are no conflicts of interest.

Funding Research was supported by the National Nature Science Foundation of China (41201518), Shandong Province Natural Science Foundation, China (ZR2019MC028, ZR2020MC037), Project of 
Shandong Province Higher Educational Science and Technology Program (J18KA138) and SDUT \& Zhangdian District Integration Development Project.

Authors' contributions ZQY designed and set up the experiment. JYZ analysed the experimental data and was a major contributor in drafting the paper. NS analysed and interpreted the MDA contents. JYS analysed and interpreted the antioxidant enzymes. BW analysed Mitochondrial enzymes. XRC analysed Comet experiment. ZHL analysed gene expression. JL collected and fed the planarians. BSZ did data analysis and redrafting of the manuscript. All authors read and endorsed the latest version of the manuscript.

Acknowledgements Not applicable

Conflict of Interest: The authors declare that there are no conflicts of interest.

\section{References}

1. Akakabe Y, Tamura Y, Iwamoto S, Takabayashi M, Nyuugaku T (2006) Volatile organic compounds with characteristic odor in bamboo vinegar. Biosci Biotechnol Biochem 70 (11): 2797-2799

2. Cai KZ, Jiang ST, Ren C, He YJ (2012) Significant damage-rescuing effects of wood vinegar extract in living Caenorhabditis elegans under oxidative stress. J Sci Food Agric 92(1): 29-36

3. Feng MB, He Q, Meng LJ, Zhang XL, Sun P, Wang ZY (2015) Evaluation of single and joint toxicity of perfluorooctane sulfonate, perfluorooctanoic acid, and copper to Carassius auratus using oxidative stress biomarkers. Aquat Toxicol 161: 108-116

4. Franken C, Koppen G, Lambrechts N, Govarts E, Bruckers L, Hond ED, Loots I, Nelen V, Sioen I, Nawrot ST, Baeyens W, Van Larebeke N, Boonen F, Ooms D, Wevers M, Jacobs G, Covaci A, Schettgen T, Schoeters $G$ (2017) Environmental exposure to human carcinogens in teenagers and the association with DNA damage. Environ Res 152: 165-174

5. Hagner M, Penttinen OP, Tiilikkala K, Setälä, H (2013) The effects of biochar, wood vinegar and plants on glyphosate leaching and degradation. Eur J Soil Biol 58: 1-7

6. Hu XC, Andrews DQ, Lindstrom AB, Bruton TA, Schaider LA, Grandjean P, Lohmann R, Carignan CC, Blum A, Balan SA, Higgins CP, Sunderland EM (2016) Detection of poly- and perfluoroalkyl substances (PFASs) in U. S. drinking water linked to industrialsites, military fire training areas, and wastewater treatment plants. Environ Sci Technol Lett 3 (10): 344-350

7. Huang QY, Zhang J, Martin FL, Peng SY, Tian MP, Mu XL, Shen HQ (2013) Perfluorooctanoic acid induces apoptosis through the p53-dependent mitochondrial pathway in human hepatic cells: a proteomic study. Toxicol Lett 223: 211-220

8. Huo YJ, Liu ZX, Xuan H, Lu CB, Yu LH, Bao WB, Zhao GQ (2016) Effects of bamboo vinegar powder on growth performance and mRNA expression levels of interleukin-10, interleukin-22, and interleukin25 in immune organs of weaned piglets. Anim Nutr 2: 111-118 
9. Ireland D, Bochenek V, Chaiken D, Rabeler C, Onoe S, Soni A, Collins SE (2020) Dugesia japonica is the best suited of three planarian species for high-throughput toxicology screening. Chemosphere 253: 126718

10. Kawamoto K, Oashi T, Oami K, Liu W, Jin YH, Saito N, Sato I, Tsuda S (2010) Perfluorooctanoic acid (PFOA) but not perfluorooctane sulfonate (PFOS) showed DNA damage in comet assay on Paramecium caudatum. J Toxicol Sci 35(6): 835-841

11. Li K, Gao P, Xiang P, Zhang XX, Cui XY, Ma LQ (2017) Molecularmechanisms of PFOA-induced toxicity in animals and humans: Implications for health risks. Environ Int 99: 43-54

12. Lindstrom AB, Strynar MJ, Libelo EL (2011) Polyfluorinated compounds: past, present, and future. Environ Sci Technol 45 (19): 7954-7961

13. Lisa FD, Kaludercic N, Carpi A, Menab`o R, Giorgio M (2009) Mitochondrial pathways for ROS formation and myocardial injury: the relevance of $\mathrm{p} 66^{\text {Shc }}$ and monoamine oxidase. Basic Res Cardiol 104 (2): 131-139

14. Liu CS, Yu K, Shi XJ, Wang JX, Lam P, Wu R, Zhou BS (2007) Induction of oxidative stress and apoptosis by PFOS and PFOA in primary cultured hepatocytes of freshwater tilapia (Oreochromis niloticus). Aquat Toxicol 82: 135-143

15. Loo AY, Jain K, Darah I (2007) Antioxidant and radical scavenging activities of the pyroligneous acid from a mangrove plant, Rhizophora apiculata. Food Chem 104: 300-307

16. Ma XH, Wei Q, Zhang SS, Shi L, Zhao Z (2011) Isolation and bioactivities of organic acids and phenols from walnut shell pyroligneous acid. J Anal Appl Pyroly 91: 338-343

17. Mathew S, Zakaria ZA (2015) Pyroligneous acid-the smoky acidic liquid from plant biomass. Appl Microbiol Biotechnol 99(2): 611-622

18. Mathew S, Zakaria ZA, Musa NF (2015) Antioxidant property and chemical profile of pyroligneous acid frompine apple plant waste biomass. Process Biochem 50: 1985-1992

19. Oramahi HA, Yoshimura T (2013) Antifungal and antitermitic activities of wood vinegar from Vitex pubescens Vahl. J Wood Sci 59: 344-350.

20. Petchpoung K, Soiklom S, Siri-Anusornsak W, Khlangsap N, Tara A, Maneeboon T (2020) Predicting antioxidant activity of wood vinegar using color and spectrophotometric parameters. Methods X 7: 100783

21. Pietta PG (2000) Flavonoids as antioxidants. J Nat Prod 63: 1035-1042

22. Polthanee A, Kumla N, Simma B (2015) Effect of Pistia stratiotes, cattle manure and wood vinegar (pyroligneous acid) application on growth and yield of organic rainfed rice. Paddy Water Environ 13(4): 337-342

23. Srinivasan S, Avadhani NG (2012) Cytochrome c oxidase dysfunction in oxidative stress. Free Radic Biol Med 53: 1252-1263

24. Stahl T, Daniela MD, Brunn H (2011) Toxicology of perfluorinated compounds. Environ Sci Euro 23: 38 
25. Stockwell BR, Friedmann Angeli JP, Bayir H, Bush Al, Conrad M, Dixon SJ, Fulda S, Gasco'n S, Hatzios SK, Kagan VE, Noel K, Jiang XJ, Linkermann A, Murphy ME, Overholtzer M, Oyagi A, Pagnussat GC, Park J, Ran Q, Rosenfeld CS, Salnikow K, Tang DL, Torti FM, Torti SV, Toyokuni S, Woerpel KA, Zhang DD (2017) Ferroptosis: a regulated cell death nexus linking metabolism, redox biology and disease. Cell 171: 273-285

26. Wang B, Li DP, Yuan ZQ, Zhang YJ, Ma X, Lv ZH, Xiao Y, Zhang JY (2020) Evaluation of joint effects of perfluorooctane sulfonate and wood vinegar on planarians, Dugesia japonica. Environ Sci Pollut Res 27: 18089-18098

27. Wei Q, Ma XH, Zhao Z, Zhang SS, Liu SC (2010) Antioxidant activities and chemical profiles of pyroligneous acids from walnut shell. J Anal Appl Pyrol 88: 149-154

28. Wielsøe M, Long MH, Ghisari M, Bonefeld-Jørgensen CE (2015) Perfluoroalkylated substances (PFAS) affect oxidative stress biomarkers in vitro. Chemosphere 129: 239-245

29. Xu D, Li C, Wen Y, Liu W (2013) Antioxidant defense system responses and DNA damage of earthworms exposed to perfluorooctane sulfonate (PFOS). Environ Pollut 174: 121-127

30. Yan L, Kim IH, Huh K (2012) Influence of bamboo vinegar supplementation on growth performance, apparent total tract digestibility, blood characteristics, meat quality, fecal noxious gas content, and fecal microbial concentration in finishing pigs. Livest Sci 144: 240-246

31. Yang JF, Yang CH, Liang MT, Gao ZJ, Wu YW, Chuang LY, (2016) Chemical composition, antioxidant, and antibacterial activity of wood vinegar from Litchi chinensis. Molecules 21(9): E1150

32. Yuan ZQ, Miao ZL, Gong XN, Zhao BY, Zhang YY, Ma HD, Zhang JY, Zhao BS (2017) Changes on lipid peroxidation,enzymatic activities and gene expression in planarian (Dugesia japonica) following exposure to perfluorooctanoic acid. Ecotoxicol Environ Saf 145: 564-568

33. Yuan ZQ, Zhang JY, Zhang YL, Zhen H, Sun YQ (2015) The Effect of Perfluorooctanoic Acid on the planarian Dugesia japonica. Pol J Environ Stud 24: 801-807

34. Yuan ZQ, Zhang JY, Meng W, Zhou Y (2014) Effects of perfluorooctane sulfonate on behavioral activity, regeneration and antioxidant enzymes in planarian Dugesia japonica. Chem Ecol 30 (2): 187195

35. Yuan ZQ, Zhang JY, Tu CC, Wang ZJ, Xin WP (2016) The protective effect of blueberry anthocyanins against perfluorooctanoic acid-induced disturbance in planarian (Dugesia japonica). Ecotox Environ Safe 127: 170-174

36. Zhang YC, Wang X, Liu BJ, Liu Q, Zheng H, You XG, Sun K, Luo XX, Li FM (2020) Comparative study of individual and co-application of biochar and wood vinegar on blueberry fruit yield and nutritional quality. Chemosphere 246: 125699

37. Zulkarami B, Ashrafuzzaman M, Husni MO, Ismail MR (2011) Effect of pyroligneous acid on growth, yield and quality improvement of rockmelon in soilless culture. Aust J Crop Sci 5: 1508-1514

\section{Figures}




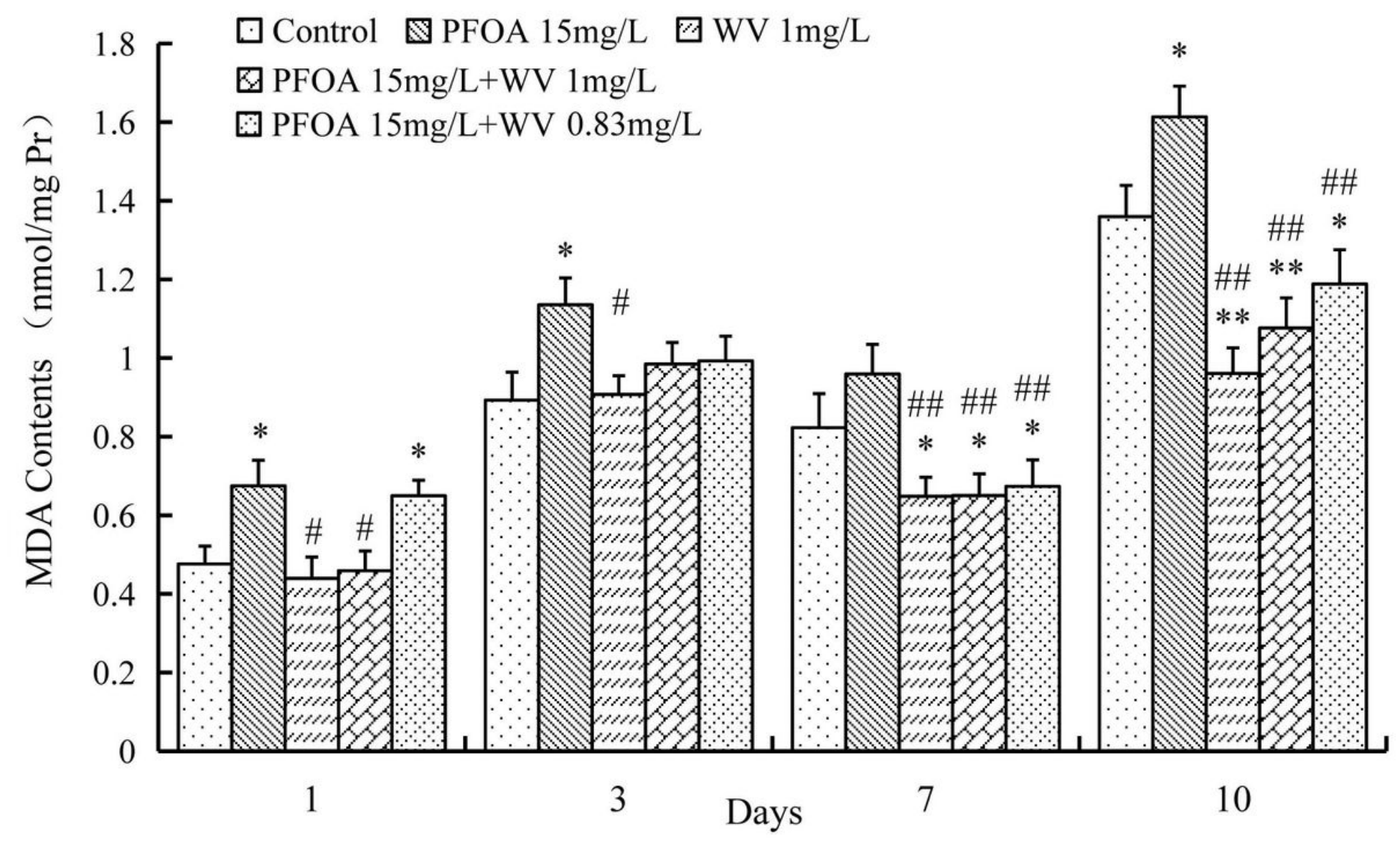

Figure 1

Evaluation the MDA contents of planarians after exposed to PFOA and WV. * and ** represent significance as compared to control; \# and \#\# represent significance as compared to the PFOA group. 

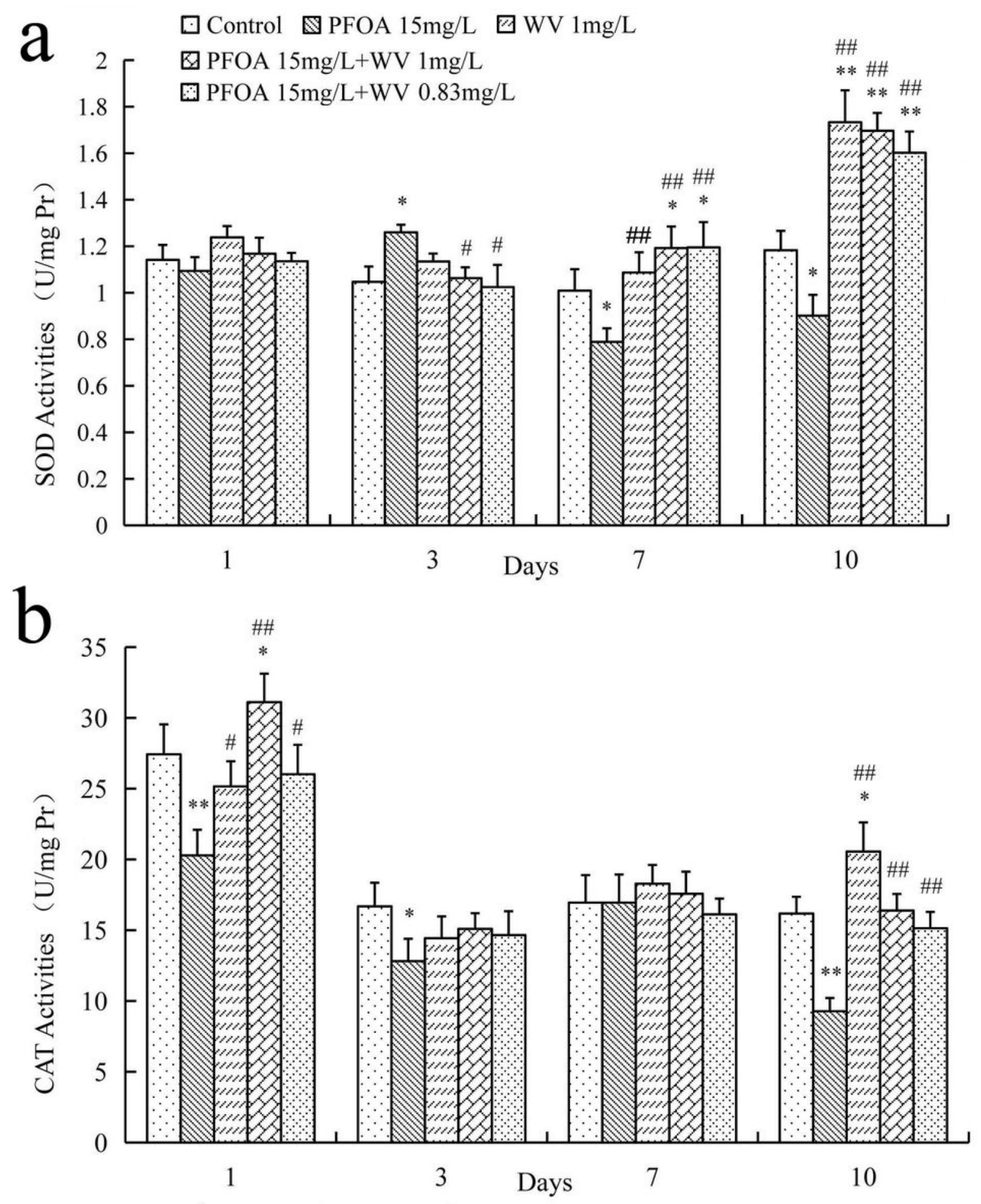

Figure 2

The enzyme activities changes of planarians after exposed to PFOA and WV: (a) SOD and (b) CAT. * and ** represent significance as compared to control; \# and \#\# represent significance as compared to the PFOA group. 

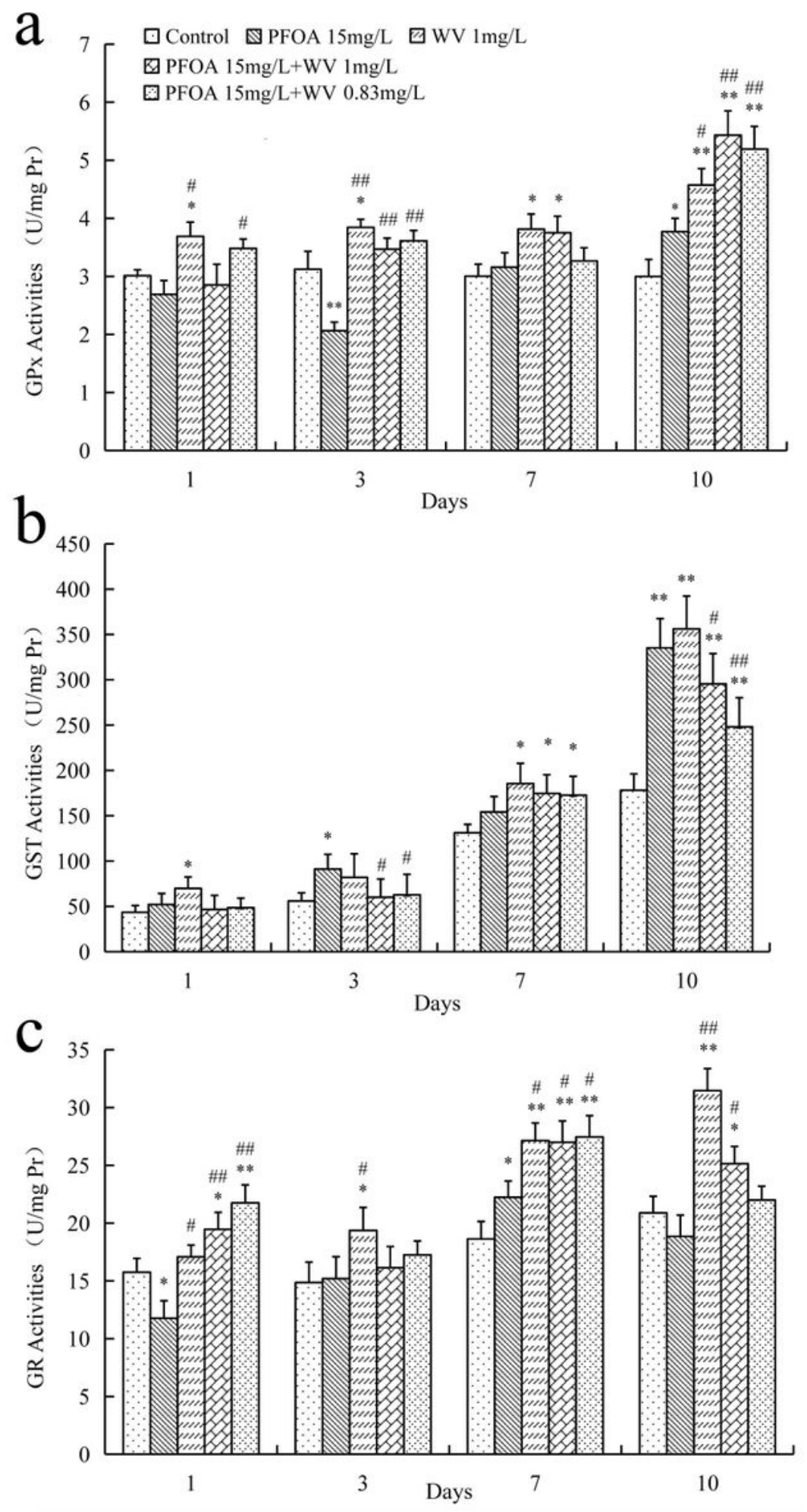

\section{Figure 3}

The activities changes of enzyme associated with glutathione in planarians after exposed to PFOA and WV: (a) GPx, (b) GST and (c) GR. * and ** represent significance as compared to control; \# and \#\# represent significance as compared to the PFOA group. 

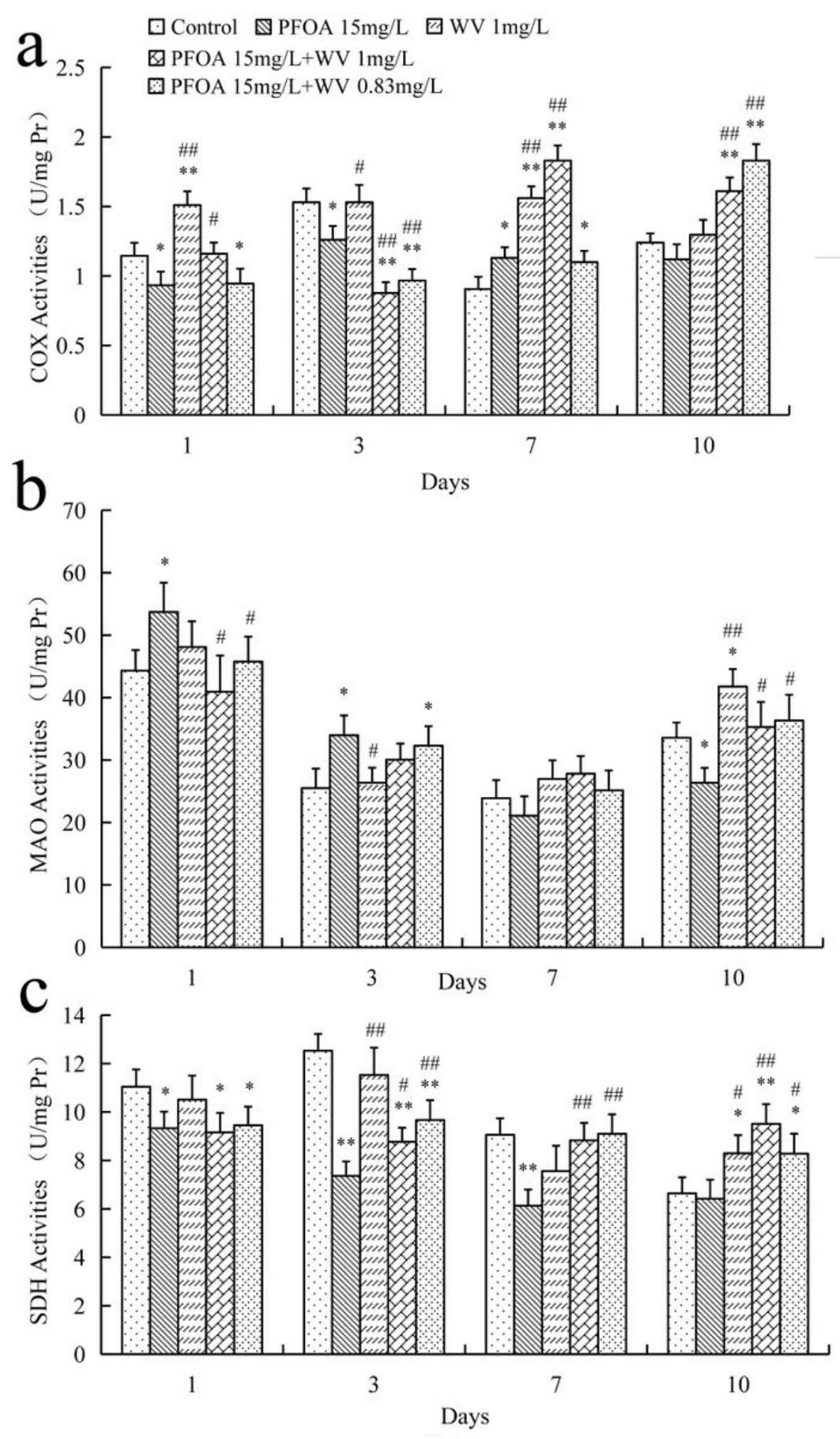

\section{Figure 4}

The enzyme activities changes in mitochondrion of planarians after exposed to PFOA and WV: (a) COX, (b) MAO and (c) SDH. The mitochondria were isolated and the activities were determined by kit. * and ** represent significance as compared to control; \# and \#\# represent significance as compared to the PFOA group. 

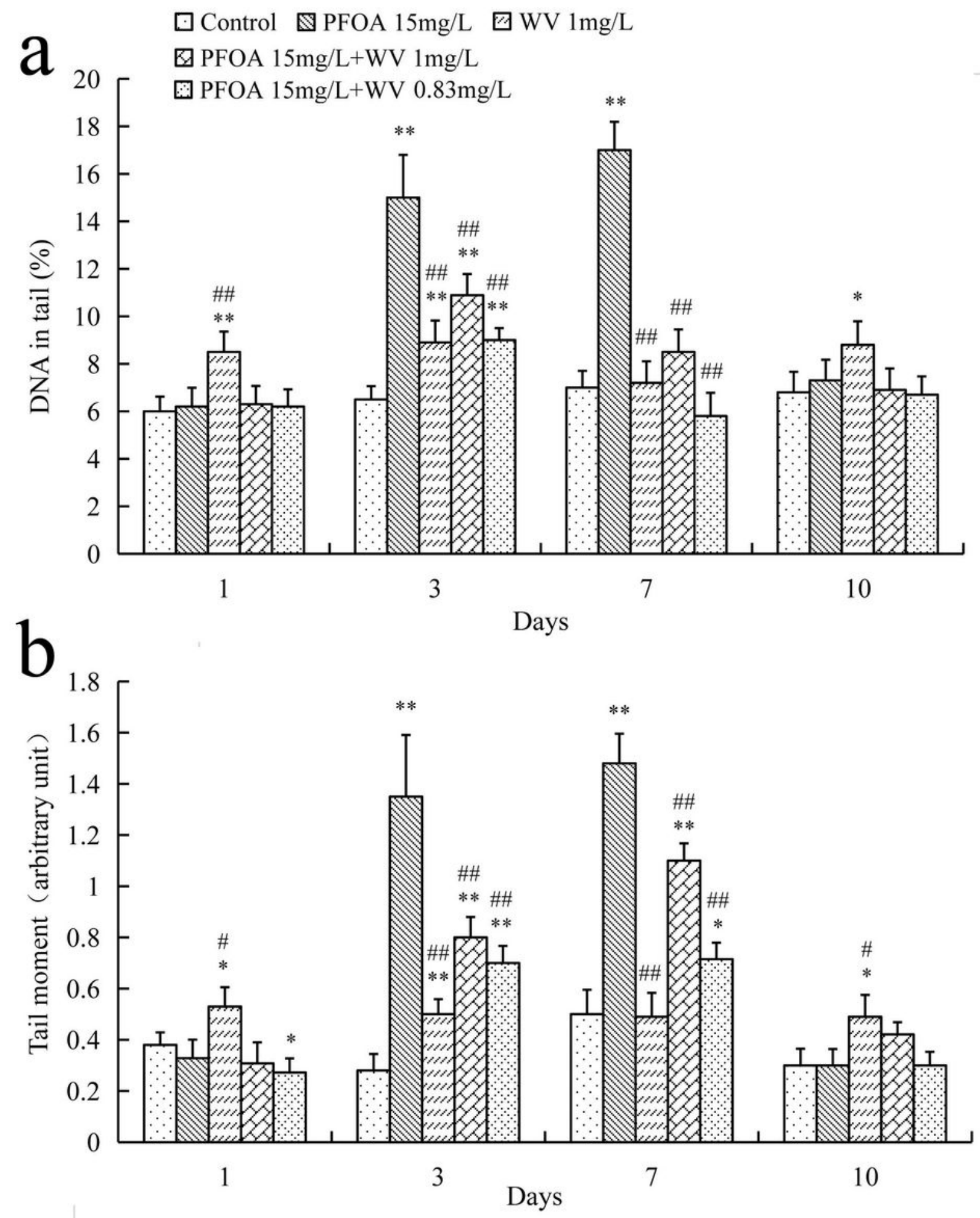

Figure 5

The DNA damage (a) DNA in tail (\%) and (b) Olive tail moment were measured by CASP comet analysis software in planarians after exposed to PFOA and WV. * and ** represent significance as compared to control; \# and \#\# represent significance as compared to the PFOA group. 

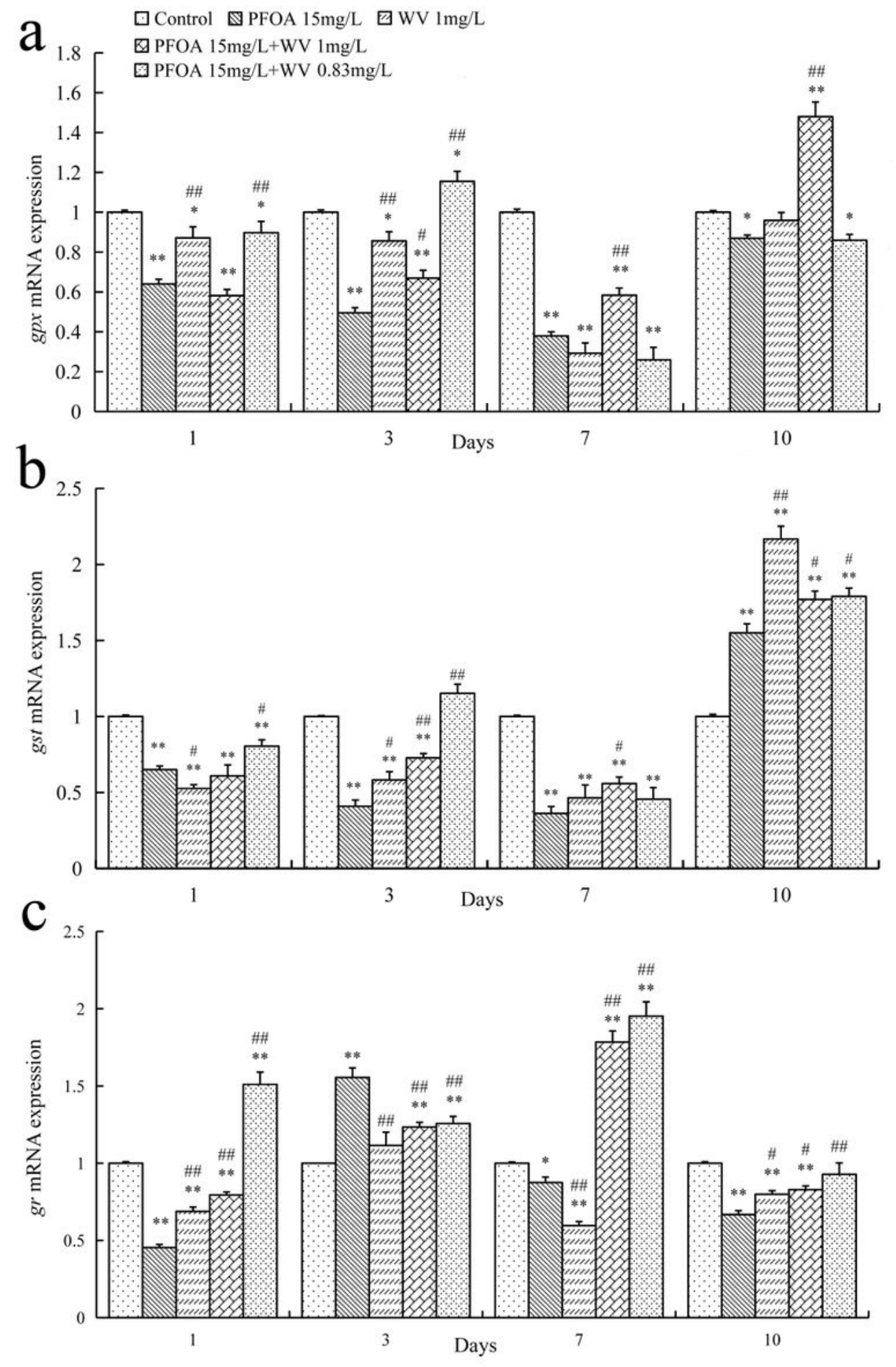

\section{Figure 6}

The relative expression levels of genes associated with glutathione in planarians after treatment with PFOA and WV: (a) gpx, (b) gst and (c) gr genes. qRT-PCR and $\beta$-actin of planarians as internal reference gene were used to measure the changes of gene expression with the delta-ct method. * and ** represent significance as compared to control; \# and \#\# represent significance as compared to the PFOA group. 